\title{
HISTORY AND TROUBLES OF CONSUMER SURPLUS
}

\author{
Miroslav Svoboda*
}

\begin{abstract}
:
The paper is focused on history of the concept of consumer surplus presented by Alfred Marshall as an economic tool to measure benefits and losses resulting from changes in market conditions. As it assumes constant marginal utility of money, it was refused by further development of economics. Subsequently, John Hicks redefined the concept using indifference analysis, inducing the use of compensating and equivalent variations in welfare economics. However, we reveal substantial errors in the Kaldor-Hicks-efficiency justification of economic policy and suggest an alternative use for the concept of consumer surplus - in an analysis of economic discrimination.
\end{abstract}

Keywords: consumer surplus, compensating variation, Alfred Marshall, John Hicks

JEL Classification: D61, N30

The concept of consumer surplus can be found in every standard economic textbook. It serves as a simple and clear tool for measuring welfare effects of exchange. And yet, in the field of economic theory, the concept has been subject to long-running dispute since Alfred Marshall put it into his Principles of Economics.

It seems that the consumer-surplus controversy has not been settled down, and yet the use of the concept in standard economic analysis is widespread and seemingly uncontroversial. Therefore the issue needs further attention and evaluation. The present article seeks to contribute to filling the gap by providing a form of introduction. It deals not only with history of the concept but also tries to stress its weak points. In addition, it tries to identify the direction in which consumer surplus might serve as a useful tool for empirical economic research.

The structure of the paper is as follows: In the first section we introduce Alfred Marshall's concept of consumer surplus and discuss its underlying assumptions; subsequent section describes Hicks's redefinition and development of the concept. In the third section we reveal substantial errors in Hicks's and Kaldor's application of the concept in the field of economic policy. Final section suggests an alternative use for the whole concept of consumer surplus.

\section{Alfred Marshall's Consumer Surplus}

Alfred Marshall's Principles of Economics, first published in 1890, introduced (among other things) a theory of consumer and producer behaviour, derived demand and supply

* University of Economics, Prague (svobodam@vse.cz). 
curves and used them in partial equilibrium analysis, of which the concept of consumer surplus was an integral part. It prompted an immediate attention of Marshall's contemporaries and was considered to be a striking novelty (provoking also a huge critique). ${ }^{1}$

In his book, Marshall could not leave the old question about price and value (or utility) without attention. As marginal analysis suggests, price paid does not represent the value of an object. Moreover, in most cases one would be willing to pay more than he or she actually pays rather than go without the good. A person "thus derives from the purchase a surplus of satisfaction". ${ }^{2}$ If price is not a measure of utility, is there a way how to measure the increment of satisfaction, which an exchange yields? Marshall seems to find one:

"The excess of the price ${ }^{3}$ which he would be willing to pay rather than go without the thing, over that which he actually does pay, is the economic measure of this surplus satisfaction. It may be called consumer's surplus." 4

Marshall does not stop with defining a measure of the "surplus satisfaction". He also suggests a way of computing and representing it graphically with the aid of a demand curve. Figure 1 presents his original representation.

Figure 1

\section{Demand for Tea (from Principles of Economics)}

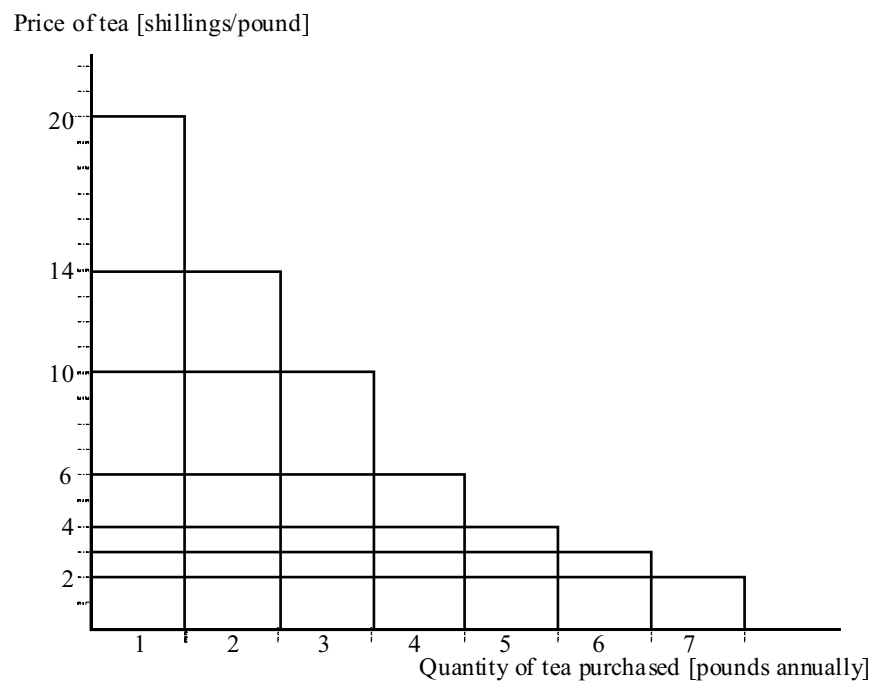

1 As it happens, Alfred Marshall was not completely original. The first person to have developed a concept of consumer surplus, and moreover, identified its size with an area under a demand curve and above a price line, was Jules Dupuit, a French engineer, in his articles "De la mesure de l'utilité des travaux publics" (1844) and "De l'influence des péages sur l'utilité des voies de communication" (1849). Nevertheless, it was Alfred Marshall who presented the concept to the economic community at large and it is to his interpretation that the whole debate has been directed. Hence in this article we deal principally with Marshall's concept.

2 Marshall (1947 [1920]), p. 124. Marshall's Principles of Economics got eight editions. Through the time, he had enriched it with some modifications and notes on account of the proceeding discussion. Therefore, the last edition is used here as a reference.

3 We should probably read it as "total expenditure" instead of "price".

4 Ibid., p. 124. 
Figure 1 shows quantity of tea demanded by a particular man at different prices. If he actually buys 7 pounds of tea at the price of 2 shillings, what is the total utility of tea for him (in money terms)? Surely it is much more than the 14 shillings paid. Looking at the demand curve we see that for the price of 20 he would have bought 1 pound of tea, demonstrating that his satisfaction (marginal utility) gained from that single pound is no less than 20 shillings. If the price fell to 14 shillings, he would be induced to buy not just 1 but 2 pounds, which shows not only that the second pound is worth no less than 14 shillings to him, but also that the first pound (actually bought for 14 but previously demanded even for 20 shillings) yields a surplus satisfaction worth to him at least 6 shillings, etc.

When he purchases 7 pounds of tea, it means he gets total utility of at least $20+14+10+6+4+3+2=59$ shillings while paying only 14 shillings, and thus experiencing a surplus of satisfaction of no less than $18+12+8+4+1+0=43$ shillings. That is exactly the size of the area above the price-line and under the demand curve! The elegance and simplicity of such a representation of one's surplus of utility is appealing. And probably that is the main reason why it is commonly used at school and so well-remembered among undergraduate students of economic science.

On the other hand, students mostly do not remember one crucial fact: the above mentioned method of computing the consumer surplus definitely cannot be a general case, containing some important and limiting assumptions. In general, the price that a person is willing to pay for a marginal unit of a good is dependent on the price that he or she paid for the preceding units. Thus if the man in our example purchased 7 pounds of tea for a price of 2 shillings, he was willing to buy the $7^{\text {th }}$ unit only because all the preceding units cost the same. Were he forced to pay a different price for them, say the maximum price for each pound, his situation would definitely change - his income would fall and he would possibly stop buying tea long before the $7^{\text {th }}$ pound as tea would represent bigger sacrifice of other goods than before (or because he would exhaust his income completely).

\section{Constant Marginal Utility of Money}

Marshall made a strong assumption to avoid such a problem: he declared the marginal utility of money (approximately) constant:

"We tacitly assumed that the sum which purchasers were willing to pay, and which sellers were willing to take ... would not be affected by the question whether the earlier bargains had been made at a high or a low rate."

He considered this assumption perfectly justifiable as it fitted well the frame of his concept of partial equilibrium analysis. He was concerned with market situations where each individual spends only small fraction of his or her resources and (or) where price changes are only small. For Marshall, the ceteris paribus clause is a relevant tool then; exploring a particular market, we do no harm if we omit the impact on other goods or income.

5 Ibid., p. 334. 
"Strictly speaking we ought to take account of the fact that if he spent less on tea, the marginal utility of money to him would be less than it is, and he would get an element of consumer's surplus from buying other things at prices which now yield him no such rent. But these changes of consumers' rent (being of the second order of smallness) may be neglected, on the assumption, which underlies our whole reasoning, that his expenditure on any one thing, as, for instance, tea, is only a small part of his whole expenditure." 6

Without such an assumption, the whole conception of consumer surplus would not be consistent, as it is composed of three perspectives (or "definitions"): (1) consumer surplus as a surplus of satisfaction (further referred to as "C.S.1"), (2) consumer surplus as an excess expenditure ("C.S.2"), and (3) consumer surplus as an area under the demand curve and above the price line ("C.S.3"). In general, the three perspectives are of different meaning. But if the marginal utility of money is constant, it can serve as a cardinal index of utility - hence C.S.2 is an appropriate measure of C.S.1. ${ }^{7}-$ and, with the marginal utility of money constant, the demand curve merges with the marginal utility curve - thus C.S. 3 is an exact measure of C.S. $2^{8}$

\section{Total Consumer Surplus}

Nevertheless, limitations imposed by the constancy assumption are very strict. First of all, as it is to be used for small changes only, one could possibly conceive of measuring a change in a consumer surplus but not the surplus as a whole. Many goods are a necessity: were an individual to be deprived of them altogether, he or she would be willing to sacrifice everything, subject to his or her budget constraint. Thus C.S.2 ceases to be a good measure of C.S.1. In addition, C.S.1 could be infinitely large and therefore without any reasonable meaning.

Being aware of it, Alfred Marshall tried to escape:

"We must therefore take life for granted, and estimate separately the total utility of that part of the supply of the commodity which is in excess of absolute necessaries..."9

Such an attempt is tantamount to a tacit confession that even in Marshall's cardinal concept of utility, an unambiguous way of measuring total utility cannot be found.

\section{Aggregation over Different Goods}

The constant marginal utility of money assumption is closely related to Marshall's assumption of independent utility functions: he assumes that utility from a particular good is not affected by utility of other goods. Thus quantity demanded of a good

$6 \quad$ Ibid., p. 842 (Mathematical Appendix, Note VI.).

7 Actually, it has to be stressed that C.S.2 is never an exact measure of C.S.1, if C.S.1 is defined simply as a satisfaction gained from a purchase. A person always gets a surplus satisfaction from a voluntary exchange (C.S.1>0), even when he or she pays the maximum price (C.S. $2=0$ ).

8 Some disputes were also held as for which consumer surplus is the "true" one. It is to be stressed that generally speaking, no definition of a man-made term can be "true" as the term is not a property of anyone. However, it is of importance to know which definition is used by whom. As for Marshall's consumer surplus, I agree with Bishop (1943) that Marshall saw the C.S.1 as the primary one and the others two as measures of it.

9 Ibid., p. 841 (Mathematical Appendix, Note VI.). 
depends solely on its price but not on the prices and quantities demanded of other goods. (For Marshall, again, this condition of "other things being equal" is justifiable as he considers small changes and small expenditures only.)

But is there a way from a single good to a consumer surplus of many (or all) goods? Marshall recognizes that some goods are substitutes or complementary to each other and that their aggregate consumer surplus is not just a sum of particular surpluses, as we can see if we deprive an individual from his/her consumption. Were he or she deprived of both rival goods, say tea and coffee, the loss would be bigger than a sum of losses were he or she deprived of just one of them, the other one still being available. If it was for two complementary goods, the total loss would be smaller.

Marshall thought about grouping some particular goods together as one commodity to make the calculation of an aggregate consumer surplus possible. However, he himself did not consider the project a success:

"But the task of adding together the total utilities of all commodities, so as to obtain the aggregate of the total utility of all wealth, is beyond the range of any but most elaborate mathematical formulæ. An attempt to treat it by them some years ago convinced the present writer that even if the task were theoretically feasible, the result would be encumbered by so many hypotheses as to be practically useless." 10

It does not seem useful to measure the total consumer surplus of an individual. Are we dealing with "small changes" then? How can we define them? And how can we hold the marginal utility of money constant, speaking of total consumption possibilities and thus of income as a whole?!

\section{Aggregation over Different Consumers}

Marshall made also an attempt to aggregate the total surplus of consumers at a particular market. As the consumer surplus is measured by the triangle-like area under the demand curve and above the price-line, the consumers' surplus can be measured, according to Marshall, exactly the same way, only using the market demand curve.

This necessarily means Marshall's cardinal measure of utility - money - is of the same value-schedule to every person:

"...it would naturally be assumed that a shilling's worth of gratification to one Englishman might be taken as equivalent with a shilling's worth to another, 'to start with,' and 'until cause to the contrary were shown'.".

Subsequently, Marshall abandons the constancy of marginal utility of money and admits that satisfaction derived from a money unit differs between "an ordinary poor" and "an ordinary rich" man. There are cases in which a correction in this way would be needed. Nevertheless:

"On the whole, however, it happens that by far the greater number of the events with which economics deals, affect in about equal proportions all the different classes of society; so that if money measures of the happiness caused by two events are equal, there is not in general any very great difference between the amounts of the happiness in

10 Ibid., p. 131, footnote 1.

11 Ibid., p. 130. 
the two cases. And it is on account of this fact that the exact measurement of the consumers' surplus in a market has already much theoretical interest, and may become of high practical importance."12

Marshall's interpersonal comparison of people's satisfaction prompted huge critique which does not need to be repeated here. Together with the measurability of utility it was dismissed by further development of economic science as soon as indifference analysis was developed. Still, it has an appeal which preserved it from being forgotten: it was the only tool (with an ambition to be a scientific one) to measure welfare effects of changes in market conditions.

\section{Hicksian Consumer Surplus}

After ordinalism was introduced to economics, the concept of consumer surplus "suffered" from being tied with measurability of utility and interpersonal comparison of utility. The situation had not changed until John R. Hicks redefined the whole concept with the aid of indifference analysis in the 1930s.

Why did Hicks return to the concept of consumer surplus? The answer can be found in his 1939 article "The Foundations of Welfare Economics". His intention there was to start a normative branch of economics - welfare economics - on a secure, scientific field. He starts with an assertion that pure laissez-faire economics does not necessary lead to an optimum structure of production and consumption. There might be another situation in which the economy would be more effective but which at the same time cannot be achieved without an economic policy that brings benefits to some but losses for others. However, how can we judge the superiority of the latter situation, when the scientific interpersonal comparisons of utility are impossible? There is a way, says Hicks. If the benefits are so great that all the losses of damaged people can be compensated and still something is left, than the reorganization will produce a net social advantage; the original position was not optimum. ${ }^{13}$

To measure economic benefits and losses, we do not need to deal with utility. We simply ask for a size of compensation individuals would be willing to pay/obtain to cover their benefits/losses. From this, Hicks derives his definition of consumer surplus:

"Consumers' surplus is the measure of the compensation which consumers would need in order to maintain them at the same level of satisfaction as before, after the supply of the commodity had been withdrawn." 14

\section{Four Consumer Surpluses}

Hicks's definition was examined by Henderson (1941) who proved that Hicksian consumer surplus and the one of Marshall's (C.S.2) differs. The Marshall's surplus consists of income

12 Ibid., p. 131.

13 Hicks was not the only one who tried to get over the strict Pareto criterion of optimality in order to build new welfare economics. Kaldor (1939) followed the same line of reasoning. But let us leave the question of the so called Kaldor-Hicks efficiency aside for a while in order to concentrate on the consumer surplus only.

14 Hicks (1939), p. 710, footnote 1. 
variation which an individual needs to undergo in order to purchase the original quantity of a good, while the Hicks's surplus stands for income variation which an individual undergo in order to get the original price (to get to the original indifference curve).

This induced Hicks to explore the task more deeply in order to clear the issue:

(1) He proved that Marshall's surplus can be thought of as a special case of a general comparison of two market situations. (For Marshall, a particular exchange is compared with a situation of no purchase at all. Surely, this is a special case of comparison of two different consumption possibilities.)

(2) He showed that a difference between two market situations can be measured through the size of compensation that an individual would be willing to pay/receive in order to undergo/forego the change.

(3) He analysed the changes for both normal and inferior goods and came with a simple graphic representation.

Hicks then identified four different measures which could reasonably serve for evaluation of a market change, the number of four resulting from answering two questions: whether the change is in price or quantity, and whether the task is to achieve, or avoid the change. Hicks finally named them compensating variation, equivalent variation, compensating surplus and equivalent surplus. ${ }^{15}$ Their representation for a price fall of a normal good can be shown in Figure 2.

In Figure 2 we can see the situation of a woman with initial income of $Y_{0}$ faced with a possibility to buy good $X$ at price $p_{1}$. The optimum point would be $A$ with $X_{I}$ purchased for a total expenditure of $Y_{0} Y_{1}$, reaching indifference curve $I_{1}$. If the price were $p_{2}$, she would shift to $B$ on indifference curve $I_{2}$, buying $X_{2}$ for $Y_{0} Y_{2}$.

Figure 2

\section{Different Consumer Surpluses}

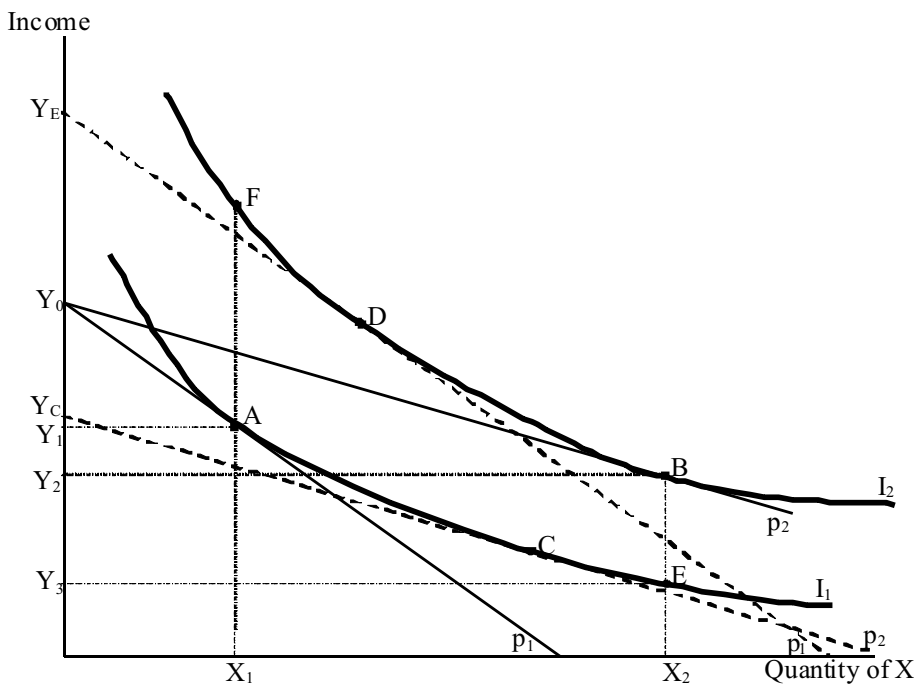

15 For the development of the debate (and terminology, too), see Hicks $(1941,1942,1943,1946)$ and also his Revision of Demand Theory (London, 1956). 
(1) How much would she be willing to pay for the privilege of purchasing at the new price rather than the old? Or, what amount of income could be extracted from her in order to compensate the price fall and leave her at the initial level of satisfaction? Clearly, the change in income needed is $Y_{0} Y_{C}{ }^{16}$ - with income $Y_{C}$ and price $p_{2}$ she would still be able to reach the initial indifference curve $I_{1}$ at $C$. The amount of $Y_{0} Y_{C}$ is called the compensating variation.

(2) What is the minimum payment she would require if the price did not fall? The amount of $Y_{0} Y_{E}$, called equivalent variation, would have to be added to her income; only after that she could reach the same level of utility $I_{2}$ as with the lower price and initial income (but now at the old price $p_{1}$, thus choosing point $D$ instead of $B$ ).

(3) If she is in the initial position (thus with the optimum at point $A$ and quantity demanded $X_{1}$ ), what amount of income would she be ready to sacrifice for a right to buy $X_{2}$ rather than stay in the initial position? This can be measured by $B E$ and it is called the compensating surplus.

It also represents the Marshallian consumer surplus (C.S.2): it is the excess of total expenditure which she would be willing to pay $\left(Y_{0} Y_{3}\right)$ rather than go without the thing (or, in this case, rather than observe price $p_{1}$ and go to the point $A$ ), above that which she actually does pay $\left(Y_{0} Y_{2}\right.$ at the point $\left.B\right)$.

For Hicks, compensating surplus would not be of much importance to welfare economics as it does not primarily concentrate on rationing. According to Hicks, after paying $B E$ the individual would not go to the point $E$ if she were free to choose; she would be able to reach a higher indifference curve by purchasing less than $X_{2}$. Thus moving her to $E$ would require a kind of coercion. ${ }^{17}$

(4) What amount of compensation would she be ready to accept in exchange for the price fall not happening, if she were planning to buy the old quantity at the lower price? Such an amount is called the equivalent surplus and can be measured by $A F$ - it will leave her on a higher satisfaction level $I_{2}$. (Hicks's comment applies to this case correspondingly.)

(If we analyse the case of price increase - the initial point being $B$-compensating measures become equivalent and vice versa: $Y_{0} Y_{C}$ is no longer compensating, but equivalent variation, $Y_{0} Y_{E}$ becomes equivalent variation; $B E$ is now equivalent surplus and $A F$ compensating surplus.)

\section{Consumer Surplus Graphically}

In works of Hicks and others, specific attention was paid to the triangle-like area under the demand curve and above the price line - which we marked C.S.3. Hicks showed that it can be a good measure of compensating surplus (C.S.2) if the income effect is

16 Strictly speaking, this answers only the latter question. The amount of $Y_{0} Y_{C}$ measures the loss of income that would leave her at the initial indifference curve. On the other hand, she would never freely pay for something that would not improve her situation; she would definitely pay less than $Y_{0} Y_{C}$ otherwise she would not get to a higher indifference curve. Mr. Hicks neglects this difference and would probably justify his position by his use of infinitesimal calculus. However, we must conclude that this position could contribute to Hicks's inability to differ between the free and the coerced action.

17 Such an argument is only half-plausible, as he tacitly assumes a possibility of coercion at the very heart of compensating principle of welfare economics! 
negligible (or zero at the best), thus proving that Marshall's assumption of constancy of marginal utility of money can be easily translated into ordinalistic language. Moreover, he proved that with income effect tending to zero, all four consumer surpluses tend towards the same size. Hicks also developed a new graphical representation of those propositions which we show here in Figure 3.

\section{Figure 3}

\section{Different Consumer Surpluses}

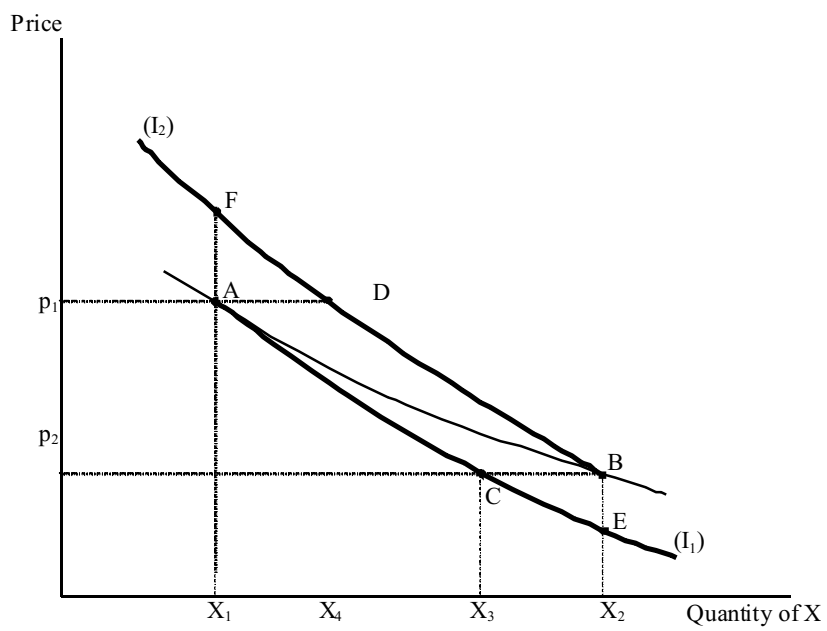

The situation in Figure 3 corresponds to that of Figure 2, except that now we measure the price of $X$ on the vertical axis. The line $A B$ is our woman's ordinary demand curve. The $A C E$ line is Hicks's compensated demand curve, which can be derived by asking: "Having bought $X_{l}$ at the price $p_{1}$, at what maximum price would she be willing to buy another unit of $X$ ? And after that, what would be the maximum price for the next additional unit? Etc." With this procedure, no new consumer surplus can appear; the whole surplus is drained from her by maximum prices paid. Along the compensated demand curve, she stays at the initial level of satisfaction, so in a sense it is a form of an indifference curve. ${ }^{18}$ The $B D F$ line is also a compensated demand curve, but compensated in the opposite way. Starting in $B$, it follows the minimum price the consumer accepts to sacrifice one unit of $X-$ and then the next unit, etc.

If we want to measure a compensating variation of price changing from $p_{1}$ to $p_{2}$, we simply compare "the most expensive" way how to get from $A$ to the lower price $p_{2}$ - the way along the compensated demand curve. Thus the consumer would get to the new price at point $C$, with total expenditure of $O p_{1} A C X_{3}$. Were the price lower from the beginning, she could purchase the same amount of $X$ for ${ }_{0} p_{2} C X_{3}$. The difference $\left(=p_{2} p_{1} A C\right)$ is the compensating variation - the maximum amount of money ready to be paid for the right of purchasing at the lower price.

18 Strictly speaking, every move along the compensated demand curve must be a shift to a higher indifference curve (otherwise the consumer would not be willing to undergo the change). In Hicks'analysis this fact is neglected. Cf. note 16. 
The compensating surplus can be reached accordingly: the most expensive way how to buy $X_{2}$ starting in $A$, is marked by the compensated demand curve with total expenditure $0 p_{1} A E X_{2}$. If she was allowed to buy $X_{2}$ at the price $p_{2}$, she would pay only $O p_{2} B X_{2}$. Thus compensating surplus is $p_{2} p_{1} A C$ minus $C B E$.

We can find equivalent variation following the other compensated demand curve which, starting in $B$, compensates the loss of every single unit of $X$ until the price $p_{2}$ is reached. The consumer initially paid $0 p_{2} B X_{2}$ and is reimbursed by $X_{4} D B X_{2}$. On the other hand, to undergo the higher price from the beginning would mean to pay $0 p_{1} D X_{4}$. Thus equivalent variation comes to $p_{2} p_{1} D B$. As for equivalent surplus, the compensated demand curve should be followed to $F$, the result then would be $p_{2} p_{1} D B$ plus AFD.

As we can see, the difference between individual measures is always tied up with a difference between ordinal and compensated demand curve. The closer they are to each other, the closer the measures are to the area $p_{2} p_{1} D B$ which is - Marshall's C.S.3! And what makes the difference between ordinal and compensated demand? It is the income effect, which is included in the ordinal but absent in the compensated demand. Thus in the case of a negligible income effect, no complicated calculation is necessary - every type of consumer surplus can be simply and reasonably expressed by the area under the (ordinal) demand curve and between the two price lines.

\section{Uses of Consumer Surplus}

Works of John Hicks and others were meant to justify the use of the consumer surplus as an economic tool:

"Consumers' surplus remains a usable instrument of analysis - as usable as it ever was; and we ought now to be enabled to use it with more security and greater confidence."19

After a quick look at the state of contemporary economic analysis, Hicks might consider himself more than successful: (1) consumer (combined with producer) surplus is widely used to judge changes of social economic welfare, and (2) the C.S.3-area is widely recognized as a plausible measure of it.

In many cases C.S.3 is used to measure a compensating variation in economic research. Why is it so, if it can be a good measure only under the assumption of negligible income effect? In our opinion, the answer is twofold. Firstly, calculation of C.S.3 is simpler than calculation of compensating variation. Even though sophisticated mathematical methods have been developed to derive Hicksian compensated demand from observable data, computation of C.S.3 is then often used instead. Second reason lies in the simplicity of C.S.3. Such a plain graphic explanation of benefits and losses attracts many economists to use it as a heuristic device at least, and often even to derive strong policy recommendations.

However, our little excursion through history creates a suspicion that such recommendations violate the frame in which its use might be relevant and justifiable. Let us turn our attention to that problem in the rest of the article.

19 Hicks (1943), p. 41. 


\section{Compensation in Welfare Economics}

We have already mentioned, what afterwards became known as the Kaldor-Hicks test of efficiency. It can be summarized as follows: if there can be a change in the structure of society that winners gain so much they are able to compensate losers and still have something left, then it is a change towards higher efficiency; it is an "ought to be" change.

If the compensation is to be paid, only one important question ${ }^{20}$ for practical economic policy remains to be answered: if the compensation shows net gain, why is it not paid by market agents themselves, by their own free will? Is economic policy necessary? The answer is not unambiguous and would probably lead us towards public goods or other concepts of market failures.

Surprisingly, for Hicks and Kaldor, such a line of reasoning would not even come to our consideration as they both exclude from the field of economic theory the very question whether the compensation is or is not being (or to be) paid!

"I do not contend that there is any ground for saying that compensation ought always to be given; whether or not compensation should be given in any particular case is a question of distribution, upon which there cannot be identity of interest, and so there cannot be any generally acceptable principle. ... If measures making for efficiency are to have a fair chance, it is extremely desirable that they should be freed from distributive complications as much as possible." 21

Kaldor $(1939$, p. 550) puts it the same way, proposing that whether the losers of a certain policy "should in fact be given compensation or not, is a political question on which the economist, qua economist, could hardly pronounce an opinion".

This seems erroneous in at least two ways: ${ }^{22}$

(1) The argument of a change to a more efficient position of an economy stands on the assumption that the compensation is actually paid. Were it not paid, the economy would shift to a different position - resources would be distributed differently and induce different structure of production. Economic analysis thus has nothing to say about efficiency of such a new position.

(2) Kaldor-Hicks test thus, quietly, brings back interpersonal comparisons of utility. It states that the change is justifiable if the monetary benefit of winners is bigger than the monetary loss of losers. However, one cannot deliberately compare what level of satisfaction an amount of money means to different people.

If and only if the losers accept the compensation, such a statement is proved. Unless this condition is fulfilled, nothing can be said about the intensity of the loss "being compensated potentially, however, not actually".

Let us illustrate this with an example of two peasants, $A$ and $B$. Both of them have a field of the same size but only $A$ possesses a plough. He is able to plough only half of his field annually, whereas $B$ could plough it whole:

20 Of course, there is a question about reliability of data, and about all the costs and risks connected to practical economic policy because of which it may eventually be refused. However, for Hicks and others, this question would lay outside the field of pure economic theory (even though they stress it is of utmost practical importance). Therefore let us leave the question aside, too.

21 Hicks (1939), pp. 711-712.

22 Cf. Š astný (2006). 
Ad (1) According to Kaldor-Hicks test, the "redistribution" of the plough from $A$ to $B$ would mean a gain in efficiency for the economy, as greater part of land would be reclaimed and as $A$ 's field could have been (as a compensation) ploughed at least as much as before. Moreover, for Kaldor and Hicks the redistribution would mean a gain in efficiency even if $B$ actually provided no compensation at all and plough his own field only, regardless of the fact that he would grow different crops and spend his earnings on different goods.

Ad (2) For Kaldor and Hicks, there is no difference among the following three questions: "what gain would $A$ be willing to accept for sacrificing the plough, if he agreed to the redistribution on his own will", "what gain to $A$ would balance his loss of the plough, were he compelled to hand it over" and "what loss would he feel, were he compelled to hand the plough over and no compensation came"?

Yet, the whole Hicks's analysis of consumer surpluses must be based on the assumption that both parties freely agree with the redistribution. The reason is clear: only at the moment of free contract (or, free exchange), the preferences may be interpersonally compared with a scientific certainty; only if $A$ actually agrees with the redistribution and compensation, we are sure that his loss is overbalanced and a net gain appears.

The free agreement is not any form of "distributive complication" as Hicks puts it; it is the only proof that a particular situation under consideration really does fit the scheme of compensating variations. The free agreement is not a problem of practical applicability of economics (see footnote 20) - it lies in the very heart of positive theory of welfare economics, therefore providing no defense for any economic policy.

\section{Final Remarks}

Consumer surplus was designed primarily to measure the welfare effects of economic policy. The history of the concept is a history of cultivation of possible definitions; nevertheless, its original ambition has remained. As this article proves, economic policy must find its justification on the other grounds. Proper calculations of consumer surplus may serve only as additional information and a guideline for further political calculations.

Yet, there is much to be said about consumer surplus. There is an area to which the concept points, even though economists rarely write about it in connection with consumer surplus - the area of (economic) discrimination. The relation is clear: the less one party may discriminate, the bigger surplus the other party experiences. The consumer surplus analysis may help to find effective methods of discrimination.

In economic textbooks, price discrimination is commonly analysed. Price is often seen as the principal measure, quantity being simply a dependent variable. For economists, out of the set of consumer surpluses, only compensating and equivalent variation are relevant - the change in price seems to be the only thing that matters.

However, the set of consumer surpluses shows that quantity matters too. There is a surplus connected to the desired quantity, not the desired price. Therefore quantity discrimination is to be analysed too (as well as a combination of price and quantity discrimination together). In the real world, firms do not face the question "what price for whom?" but more often "what price for what quantity?". Firms do not deal with infinite small steps of economists' graphs, they solve the question "how big a 'unit' of a good should be offered?" instead.

Here we can find room for further development of consumer surplus - as a tool for effective economic discrimination. 


\section{References}

Bishop, R. L. (1943), "Consumer's Surplus and Cardinal Utility". The Quarterly Journal of Economics, 57 (3, May), pp. 421-449.

Bishop, R. L. (1946), "Professor Knight and the Theory of Demand". The Journal of Political Economy, 54 (2, April), pp. 141-169.

Cannan, E. (1924), "Total Utility" and "Consumer's Surplus". Economica, (10, February), pp. 21-26.

Currie, J. M., Murphy, J. A., Schmitz, A. (1971), "The Concept of Economic Surplus and Its Use in Economic Analysis". The Economic Journal, 81, (324, December), pp. 741-799.

Dooley, P. C. (1983), "Consumer's Surplus: Marshall and His Critics". The Canadian Journal of Economics / Revue canadienne d'Economique, 16, (1, February), pp. 26-38.

Gravelle, H., Rees, R. (1992), Microeconomics. London and New York : Longman.

Hausman, J. A. (1981), "Exact Consumer's Surplus and Deadweight Loss". The American Economic Review, 71 (4, September), pp. 662-676.

Haveman, R. H., Gabay, M., Andreoni, J. (1987), “Exact Consumer's Surplus and Deadweight Loss, A Correction“. The American Economic Review, 77 (3, June), pp. 494-495.

Henderson, A. (1941), "Consumer's Surplus and the Compensating Variation". The Review of Economic Studies, 8 (2, February), pp. 117-121.

Hicks, J. R. (1939), "The Foundations of Welfare Economics". The Economic Journal, 49 (196, December), pp. 696-712.

Hicks, J. R. (1941), "The Rehabilitation of Consumers' Surplus". The Review of Economic Studies, 8 (2, February), pp. 108-116.

Hicks, J. R. (1942), "Consumers' Surplus and Index-Numbers". The Review of Economic Studies, 9 (2, Summer), pp. 126-137.

Hicks, J. R. (1943), "The Four Consumer's Surpluses". The Review of Economic Studies, 11 (1, Winter), pp. 31-41.

Hicks, J. R. (1945), "The Generalised Theory of Consumer's Surplus". The Review of Economic Studies, 13 (2), pp. 68-74.

Holman, R. et al. (2001), Dějiny ekonomického myšlení. Praha : C. H. Beck.

Houghton, R. W. (1958), "A Note on the Early History of Consumer's Surplus". Economica, New Series, 25 (97, February), pp. 49-57.

Irvine, I. J., Sims, W. A. (1998), "Measuring Consumer Surplus with Unknown Hicksian Demands". The American Economic Review, 88 (1, March), pp. 314-322.

Kaldor, N. (1939), "Welfare Propositions of Economics and Interpersonal Comparisons of Utility". The Economic Journal, 49 (195, September), pp. 549-552.

Knight, F. H. (1944), "Realism and Relevance in the Theory of Demand". The Journal of Political Economy, 52 (4, December), pp. 289-318.

Marshall, A. (1947 [1890]), Principles of Economics. London : Macmillan.

Mayer, J. (1926), "Consumer's Surplus". The American Economic Review, 16 (1, March), pp. 77-80.

Miller, H. E. (1927), "Utility Curves, Total Utility, and Consumer's Surplus". The Quarterly Journal of Economics, 41 (2, February), pp. 292-316.

Mishan, E. J. (1947), "Realism and Relevance in Consumer's Surplus". The Review of Economic Studies, 15 (1), pp. 27-33.

Pfouts, R. W. (1953), "A Critique of Some Recent Contributions to the Theory of Consumers' Surplus". Southern Economic Journal, 19 (3, January), pp. 315-333.

Š astný, D. (2006), "Konkurence a hospodářská politika: o hledání dokonalosti“. Acta Oeconomica Pragensia, 14 (2), pp. 67-83.

Varian, H. R. (1993), Intermediate Microeconomics: A Modern Approach. New York : W. W. Norton. 